\title{
Structural and magnetic properties of Mn-implanted Si
}

\author{
Shengqiang Zhou, K. Potzger, Gufei Zhang, A. Mücklich, F. Eichhorn, N. Schell, R. Grötzschel, B. Schmidt, \\ W. Skorupa, M. Helm, and J. Fassbender \\ Institute for Ion Beam Physics and Materials Research, Forschungszentrum Rossendorf, POB 510119, 01314 Dresden, Germany
}

\section{Geiger}

Institute of Structure Physics, Dresden University, Zellescher Weg 16, 01062 Dresden, Germany

(Received 6 January 2006; revised manuscript received 11 December 2006; published 7 February 2007)

\begin{abstract}
Structural and magnetic properties in Mn-implanted, $p$-type Si were investigated. High resolution structural analysis techniques such as synchrotron $\mathrm{x}$-ray diffraction revealed the formation of $\mathrm{MnSi}_{1.7}$ nanoparticles already in the as-implanted samples. Depending on the Mn fluence, the size increases from $5 \mathrm{~nm}$ to $20 \mathrm{~nm}$ upon rapid thermal annealing. No significant evidence is found for Mn substituting Si sites either in the as-implanted or annealed samples. The observed ferromagnetism yields a saturation moment of $0.21 \mu_{\mathrm{B}}$ per implanted $\mathrm{Mn}$ at $10 \mathrm{~K}$, which could be assigned to $\mathrm{MnSi}_{1.7}$ nanoparticles as revealed by a temperaturedependent magnetization measurement.
\end{abstract}

DOI: 10.1103/PhysRevB.75.085203

PACS number(s): 75.50.Pp, 82.80.Yc, 68.37.Lp, 61.10.Nz

\section{INTRODUCTION}

Recently, diluted magnetic semiconductors (DMS) have attracted huge research attention. ${ }^{1,2}$ III-V and II-IV compound semiconductors doped with transition metals (TM) by ion implantation show ferromagnetism with a Curie temperature up to room temperature. ${ }^{3,4}$ However, Si-based DMS would be preferable to compound semiconductors due to the availability of high-quality $\mathrm{Si}$ in large sizes at relatively low costs. More importantly, the fabrication of Si-based DMS is compatible with the mature microelectronics technique. Based on the Zener model, Dietl et al. ${ }^{5}$ predicted a carriermediated ferromagnet if $\mathrm{Si}$ is doped with 5\% Mn. Zhang et al. ${ }^{6}$ reported on the crystalline $\mathrm{Mn}_{0.05} \mathrm{Si}_{0.95}$ alloy with a Curie temperature up to $400 \mathrm{~K}$. Also, epitaxially grown $\mathrm{Mn}_{0.07} \mathrm{Si}_{0.93}$ thin films show ferromagnetic ordering up to $200 \mathrm{~K}$, and at the same time, possess semiconducting properties. ${ }^{7}$ In addition to the aforementioned epitaxial techniques, ion implantation is another promising method for ferromagnetic doping of semiconductors, e.g., implantation of almost any TM element with an atomic concentration exceeding those possible in thermal equilibrium by far. Very recently, Bolduc et al. ${ }^{8}$ have reported room-temperature ferromagnetism of $\mathrm{Mn}$-ion implantation $\mathrm{Si}$ at $\mathrm{Mn}$ fluences of $1 \times 10^{15} \mathrm{~cm}^{-2}$ and $1 \times 10^{16} \mathrm{~cm}^{-2}$. The Curie temperature has been evaluated to be above $400 \mathrm{~K}$ for both $n$-type and $p$-type $\mathrm{Si}$. The strength of the ferromagnetism was affected by the Mn concentration, thermal annealing, and carrier type of the $\mathrm{Si}$ substrate. The ferromagnetic coupling was believed to be carrier mediated. However, the high-resolution structural characterization of the investigated Si:Mn systems (both epitaxially grown and ion implanted) was rather limited. The diffusion of $\mathrm{Mn}$ in Si upon annealing was only investigated by Rutherford backscattering (RBS) and secondary ion mass spectrometry. ${ }^{9}, 10$ Generally $\mathrm{Mn}$ silicides are easily formed. For example, if $\mathrm{Mn}$ is deposited on $\mathrm{Si}$, an epitaxial $\mathrm{MnSi}$ is formed. ${ }^{11-13}$ Also transition metal (i.e., Co and Ni) implantation into Si can easily leads to silicides. ${ }^{14,15}$ Therefore a careful characterization of the Mn-doped Si samples has to be carried out in order to clarify the origin of the ferromag- netism, i.e., the formation of nanoparticles or a DMS system. For this purpose, in the present paper, RBS and/or channeling, transmission electron microscopy (TEM), and synchrotron radiation $\mathrm{x}$-ray diffraction (SR-XRD), are used to clarify the possible origin of the ferromagnetism in Mn-implanted $\mathrm{Si}$.

\section{EXPERIMENT}

The Mn-implanted Si samples were prepared from commercially available, Czochralski-grown single-crystal $\mathrm{Si}(001)$ wafers, which were $p$-type doped with a B concentration of $1.2 \times 10^{19} \mathrm{~cm}^{-3} . \mathrm{Mn}^{+}$ions were implanted at an energy of $300 \mathrm{keV}$ with fluences of $1 \times 10^{15} \mathrm{~cm}^{-2}, 1$ $\times 10^{16} \mathrm{~cm}^{-2}$, and $5 \times 10^{16} \mathrm{~cm}^{-2}$, which corresponds to $\mathrm{Mn}$ peak concentrations of $0.08,0.8$, and 4 at. \%, respectively, with a projected range $\left(R_{p}\right)$ of $258 \pm 82 \mathrm{~nm}$. The samples were held at $350{ }^{\circ} \mathrm{C}$ during implantation to avoid amor-

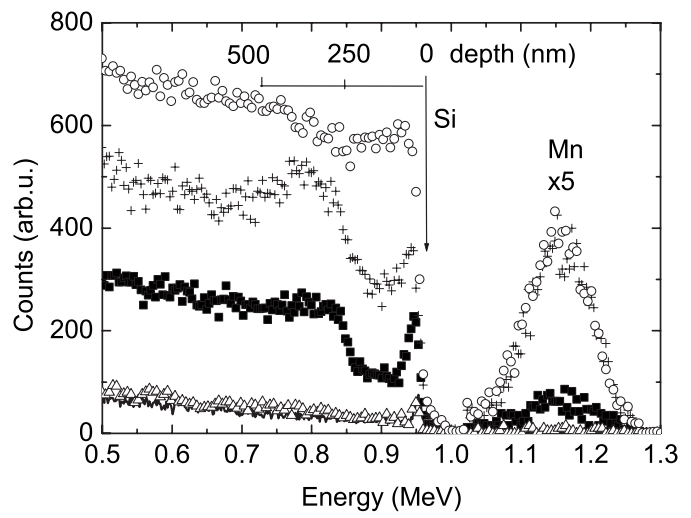

FIG. 1. RBS random and channeling along $\mathrm{Si}[001]$ spectra of as-implanted Si samples. Random $(\bigcirc)$, channeling $(+)$ for the fluence of $5 \times 10^{16} \mathrm{~cm}^{-2}$; channeling $(\square)$ for the fluence of 1 $\times 10^{16} \mathrm{~cm}^{-2}$; channeling $(\triangle)$ for the fluence of $1 \times 10^{15} \mathrm{~cm}^{-2}$; and channeling for virgin $\mathrm{Si}(-)$ which is slightly below triangle symbols. 
TABLE I. Map of structural and magnetic properties of all samples.

\begin{tabular}{|c|c|c|c|c|c|c|}
\hline $\begin{array}{l}\text { Fluence and } \\
\text { process }\end{array}$ & $\begin{array}{l}1 \times 10^{15} \mathrm{~cm}^{-2} \\
\text { as implanted }\end{array}$ & $\begin{array}{c}1 \times 10^{15} \mathrm{~cm}^{-2}, \\
\mathrm{RTA}^{\mathrm{a}}\end{array}$ & $\begin{array}{l}1 \times 10^{16} \mathrm{~cm}^{-2} \\
\text { as implanted }\end{array}$ & $\begin{array}{c}1 \times 10^{16} \mathrm{~cm}^{-2}, \\
\mathrm{RTA}^{\mathrm{a}}\end{array}$ & $\begin{array}{l}5 \times 10^{16} \mathrm{~cm}^{-2} \\
\text { as implanted }\end{array}$ & $\begin{array}{c}5 \times 10^{16} \mathrm{~cm}^{-2}, \\
\mathrm{RTA}^{\mathrm{a}},\end{array}$ \\
\hline$\chi_{\min ^{-}}-\mathrm{Si}(\mathrm{RBS} / \mathrm{C})$ & $7.4 \%$ & $6.4 \%$ & $51 \%$ & $41 \%$ & $82 \%$ & $70 \%$ \\
\hline $\begin{array}{l}\chi_{\min }-\mathrm{Mn} \\
(\mathrm{RBS} / \mathrm{C})^{\mathrm{b}}\end{array}$ & - & - & $91 \%$ & $89 \%$ & $96 \%$ & $98 \%$ \\
\hline Conv. XRD ${ }^{c}$ & No & No & No & No & No & No \\
\hline TEM $^{\mathrm{c}}$ & No & Yes & No & Yes & Yes & Yes \\
\hline SR-XRD ${ }^{c}$ & No & No & No & $\begin{array}{c}\text { Yes } \\
(11 \mathrm{~nm})^{\mathrm{d}}\end{array}$ & $\begin{array}{c}\text { Yes } \\
(6 \mathrm{~nm})^{\mathrm{d}}\end{array}$ & $\begin{array}{c}\text { Yes } \\
(15 \mathrm{~nm})^{\mathrm{d}}\end{array}$ \\
\hline $\begin{array}{l}\text { Ferromagnetism } \\
(10 \mathrm{~K})\end{array}$ & No & No & No & $\begin{array}{c}\text { Strong } \\
\left(0.21 \mu_{\mathrm{B}} / \mathrm{Mn}\right)\end{array}$ & $\begin{array}{c}\text { Weak } \\
\left(0.04 \mu_{\mathrm{B}} / \mathrm{Mn}\right)\end{array}$ & $\begin{array}{c}\text { Weak } \\
\left(0.02 \mu_{\mathrm{B}} / \mathrm{Mn}\right)\end{array}$ \\
\hline
\end{tabular}

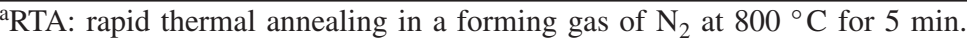

${ }^{b}$ For the Mn signal, a very weak channeling effect was observed, which reveals that the majority of implanted Mn ions are not substituted on Si sites.

"Yes" or "No" to answer if precipitates of Mn silicides are detectable by corresponding technique.

dAverage grain size.

phization. In order to reduce channeling effects, the angle between the sample surface normal and the incident beam was set to $7^{\circ}$. After implantation, rapid thermal annealing (RTA) was performed at a temperature of $800{ }^{\circ} \mathrm{C}$ for $5 \mathrm{~min}$ in a forming gas of $\mathrm{N}_{2}$. The RBS spectra were taken with a collimated $1.7 \mathrm{MeV} \mathrm{He}$ beam with a surface barrier detector at $170^{\circ}$. TEM specimens were conventionally prepared for cross-section inspection and examined on a Philips CM 30 FEG microscope. Conventional XRD (conv. XRD) measurements were performed on a Siemens D5005 diffractometer using $\mathrm{Cu}$ irradiation. SR-XRD was performed at Rossendorf beamline (ROBL) at the European Synchrotron Radiation Facility with monochromatic $\mathrm{x}$ rays of $0.1541-\mathrm{nm}$ wavelength. Magnetic properties were analyzed using a superconducting quantum interference device (SQUID) magnetometer (Quantum Design MPMS).

\section{RESULTS AND DISCUSSION}

\section{A. Mn lattice location}

After Mn-ion implantation, the samples were analyzed by RBS and/or channeling to check the implantation-induced damage and the lattice location of $\mathrm{Mn}$ with respect to the $\mathrm{Si}$ lattice. Figure 1 shows the RBS and/or channeling spectra for all samples. The Mn signals display a Gaussian distribution which corresponds to an $R_{p}$ of around $258 \mathrm{~nm}$. For samples with a fluence of $1 \times 10^{16} \mathrm{~cm}^{-2}$ and $5 \times 10^{16} \mathrm{~cm}^{-2}$, the $R_{p}$ and the amount of $\mathrm{Mn}$ agree well with SRIM simulation ${ }^{16}$ and designed values. However, for the lowest fluence sample $\left(1 \times 10^{15} \mathrm{~cm}^{-2}\right)$, the concentration of $\mathrm{Mn}$ is in the order of the detection limit. All $\chi_{\min }$ values, the ratio of the backscattering yield at channeling condition to that for a random beam incidence, ${ }^{17}$ which label the degree of lattice disordering, for $\mathrm{Si}$ and $\mathrm{Mn}$ signals are listed in Table I. As expected, a higher fluence implantation introduces a larger lattice disordering (a larger $\chi_{\min }$ ) in the silicon substrates. For the Mn signal, $\chi_{\text {min }}$ amounts to more than $90 \%$ for both samples with the fluence of $1 \times 10^{16} \mathrm{~cm}^{-2}$ and 5 $\times 10^{16} \mathrm{~cm}^{-2}$, which proves that the majority of the implanted $\mathrm{Mn}$ atoms are not substituted to Si sites with respect to the [001] crystallographic axis.

Figure 2 shows the RBS spectra for the sample implanted with $5 \times 10^{16} \mathrm{~cm}^{-2} \mathrm{Mn}$ ions after RTA annealing at $800{ }^{\circ} \mathrm{C}$ for $5 \mathrm{~min}$. The changes of $\chi_{\min }$ values are listed in Table I. The annealing process removed only a very small fraction of the implantation-induced damage (a slight decrease of $\chi_{\min }$ ) and did not change the Mn element distribution, i.e., Mn atoms did not diffuse to deep or shallow places, nor to substitutional Si sites. The other samples show similar behavior after annealing (see Table I).

\section{B. Observation of crystalline $\mathrm{MnSi}_{\mathbf{x}}$ nanoparticles}

In order to confirm the formation of Mn-silicides nanoparticles, high resolution TEM (HRTEM) was performed.

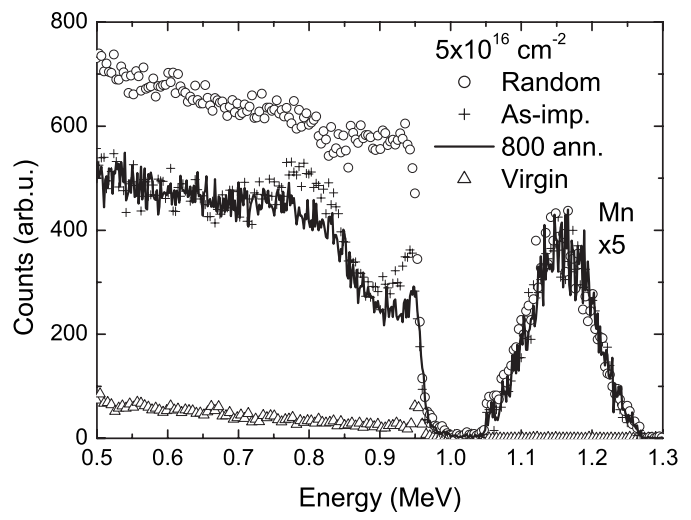

FIG. 2. RBS random and channeling along $\mathrm{Si}[001]$ spectra for sample implanted with a fluence of $5 \times 10^{16} \mathrm{~cm}^{-2}$. Random $(\bigcirc)$ and channeling $(+)$ for as-implanted sample, channeling $(-)$ for RTA sample, and channeling $(\triangle)$ for virgin Si. Only a small fraction of damage was recovered by annealing. For Mn signals, no channeling was observed either for as-implanted or annealed samples, which means Mn does not substitute Si lattice site. 

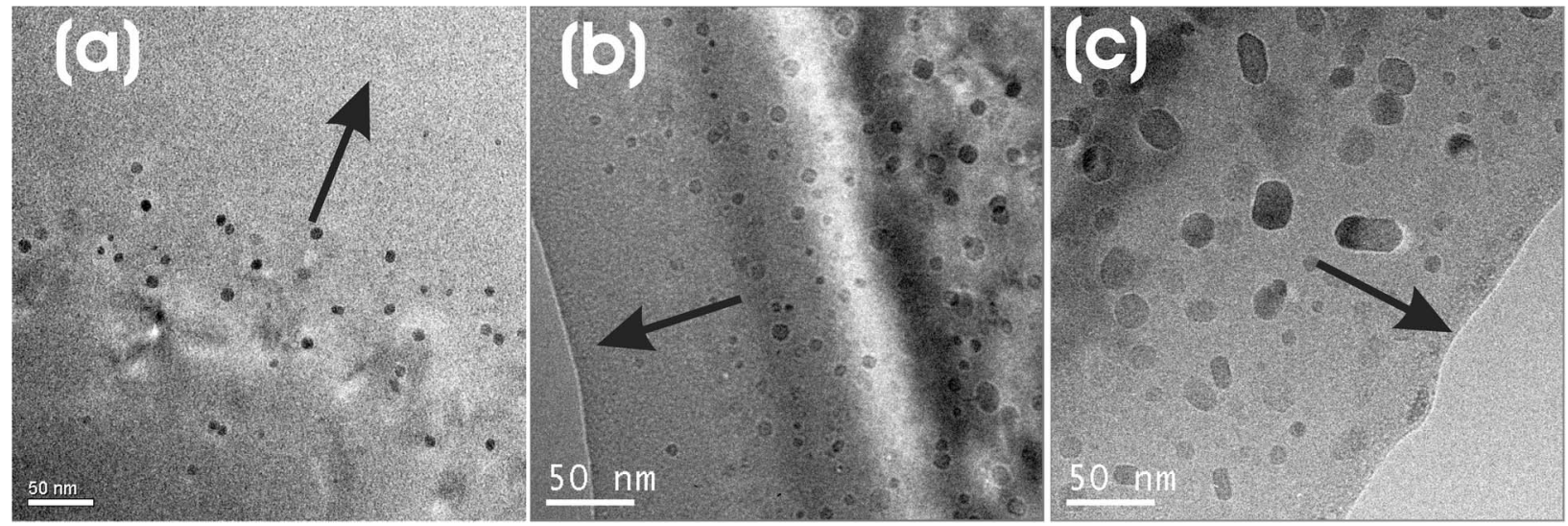

FIG. 3. TEM-overview images show the implantation induced damage and nanosized precipitates after RTA: (a) $1 \times 10^{15} \mathrm{~cm}^{-2}$, (b) 1 $\times 10^{16} \mathrm{~cm}^{-2}$, and (c) $5 \times 10^{16} \mathrm{~cm}^{-2}$. The nanosized precipitates are visible as spotlike contrast, and they are growing with increasing fluence. The arrow marks the direction towards the sample surface.

For the highest fluence $\left(5 \times 10^{16} \mathrm{~cm}^{-2}\right)$, some small nanoparticles with diameters of $\sim 5 \mathrm{~nm}$ are detected already in the as-implanted samples (not shown). Figure 3 shows typical TEM-overview images at lower magnification of samples after RTA treatment. Nanosized precipitates are unambiguously found in all annealed samples with different fluence. They exhibit mean diameters of $5 \mathrm{~nm}$ for a fluence of 1 $\times 10^{15} \mathrm{~cm}^{-2}, 10 \mathrm{~nm}$ for a fluence of $1 \times 10^{16} \mathrm{~cm}^{-2}$, and $20 \mathrm{~nm}$ for a fluence of $5 \times 10^{16} \mathrm{~cm}^{-2}$. Figures $4(\mathrm{a})$ and $4(\mathrm{~b})$ show HRTEM images for the samples of 1E16 RTA and 5E16 RTA (see Table I for the sample abbrevation). Most of those nanoparticles are spherical-like, their diameters increase from around $10 \mathrm{~nm}$ to $20 \mathrm{~nm}$ with increasing fluence. However, considering the rich varieties of $\mathrm{Mn}$ silicides ${ }^{13}$ it is extremely difficult to identify these nanoparticles even by HRTEM. ${ }^{18}$ Table II lists the structural information of some higher manganese silicides with $\mathrm{Si}$ composition of around 1.7 after Ref. 13. All different compositions are named as $\mathrm{MnSi}_{1.7}$ throughout the rest of the article. The crystallite area of some particles was Fourier-analysed as shown in Fig. 4(c). The reflections in the diffractogram indicated by arrows reveal a lattice spacing of around $1.7 \mathrm{~nm}$, which can be attributed to $\mathrm{MnSi}_{1.7}$ (see Table II).

In addition, XRD was performed in order to confirm the formation of $\mathrm{Mn}$-silicide nanoparticles. Since a conventional XRD diffractometer (Siemens D5005) failed to detect any crystalline nanoparticles in both as-implanted and annealed samples $\left(5 \times 10^{16} \mathrm{~cm}^{-2}\right)$ due to the small amount of nanoparticles and the limited intensity of $\mathrm{Cu}$-target $\mathrm{x}$-ray source, we performed XRD measurements at a synchrotron radiation source. However, also at synchrotron XRD, in a symmetric beam geometry (Bragg-Brentano) one fails to detect any $\mathrm{Mn}$ silicides in all samples (not shown). Therefore, a grazing incidence geometry was used during the measurement. Grazing incidence $\mathrm{x}$-ray diffraction (GIXRD) refers to a method where the incident $\mathrm{x}$-ray beam is aligned at a small (here $0.4^{\circ}$ ) angle to the sample surface. This has the advantage to limit the penetration depth of the $\mathrm{x}$ rays into the sample with consequently low background scattering from the substrate. Figure 5 shows GIXRD patterns of all samples. The diffraction peaks at around $42^{\circ}$ and $46.3^{\circ}$ cannot be attributed to the $\mathrm{Si}$ substrate, but to $\mathrm{MnSi}_{1.7}$ (see Table II). For the highest fluence sample $\left(5 \times 10^{16} \mathrm{~cm}^{-2}\right)$, nanoparticles were observed already in the as-implanted state, and they grew from around $5 \mathrm{~nm}$ to $15 \mathrm{~nm}$ in grain size after annealing. $\mathrm{MnSi}_{1.7}$ was also found for a fluence of $1 \times 10^{16} \mathrm{~cm}^{-2}$ after annealing, while there is no indication of any crystalline nanoparticles in the lowest fluence sample $\left(1 \times 10^{15} \mathrm{~cm}^{-2}\right)$, even after annealing. Using the Scherrer formula, ${ }^{19}$ the average size of these nanoparticles is calculated, and listed in Table I.

\section{Magnetic properties}

Figure 6 shows the magnetization versus field curves $(M-H$ loops $)$ recorded at $10 \mathrm{~K}$. The sample of 1E16 RTA shows a clear hysteretic behavior with a saturation of $0.21 \mu_{\mathrm{B}} / \mathrm{Mn}$ and a coercivity of $275 \pm 25$ Oe. In contrast, both samples of 5E16 as implanted and 5E16 RTA show very weak hysteretic behaviors. All other samples (1E16 as implanted, 1E15 as implanted, and 1E15 RTA) did not show

TABLE II. Composition and lattice parameters of tetragonal $\mathrm{MnSi}_{1.7}$ phases (after Ref. 13).

\begin{tabular}{llllll}
\hline \hline Phase & Composition & $a(\mathrm{~nm})$ & $c(\mathrm{~nm})$ & Space group & PDF number $^{\mathrm{a}}$ \\
\hline $\mathrm{Mn}_{4} \mathrm{Si}_{7}$ & 1.750 & 0.5525 & 1.7463 & $P-4 c 2$ & $72-2069$ \\
$\mathrm{Mn}_{11} \mathrm{Si}_{19}$ & 1.727 & 0.5518 & 4.8136 & $P-4 n 2$ & - \\
$\mathrm{Mn}_{15} \mathrm{Si}_{26}$ & 1.733 & 0.5525 & 6.5550 & $I-42 d$ & $20-724$ \\
$\mathrm{Mn}_{27} \mathrm{Si}_{47}$ & 1.741 & 0.5530 & 11.7940 & $P-4 n 2$ & $26-1251$ \\
\hline \hline
\end{tabular}

Inorganic crystal structure database (ICSD) 

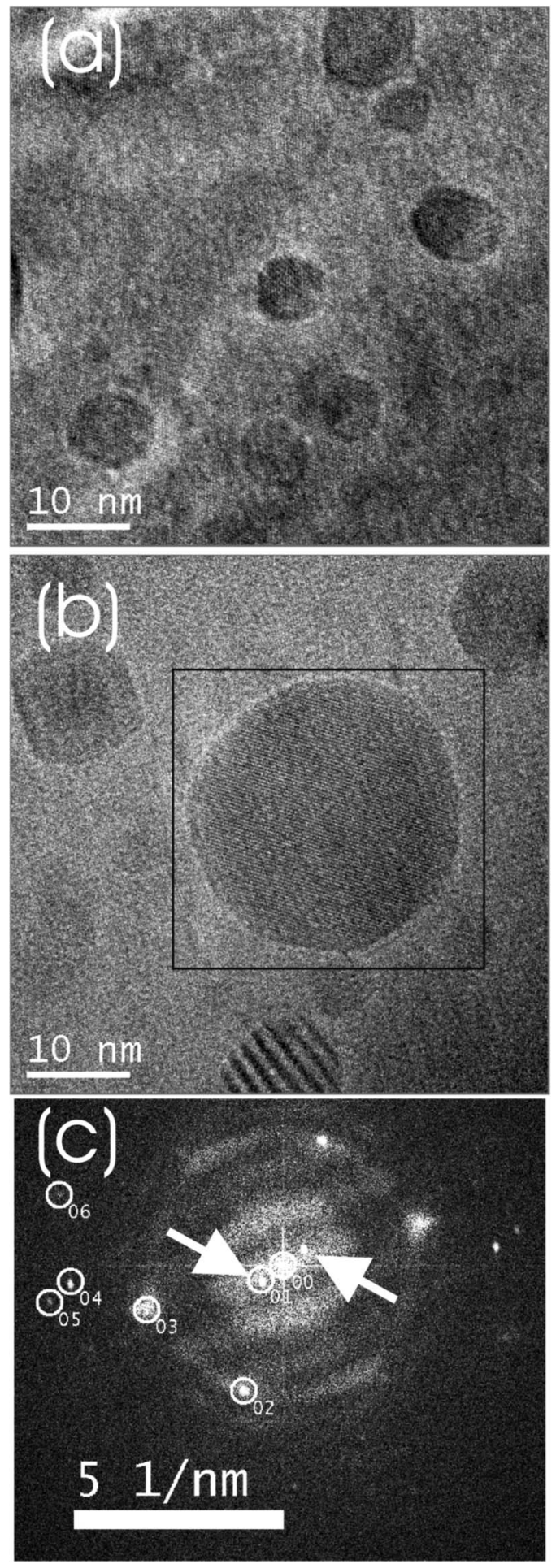

FIG. 4. High-resolution TEM images for representative $\mathrm{MnSi}_{\mathrm{x}}$ nanoparticles in (a) 1E16 RTA, (b) 5E16 RTA, and (c) the diffractogram of one nanoparticle in (b). The reflection spots marked by the arrows in (c) reveal a lattice spacing of around $1.7 \mathrm{~nm}$, which can be attributed to $\mathrm{MnSi}_{1.7}$.

any detectable magnetism (not shown here). In order to clarify the origin of the ferromagnetism of the sample $1 \mathrm{E} 16$ RTA, zero-field cooled (ZFC) and field cooled (FC) magnetization curves were measured in a field of 50 Oe from

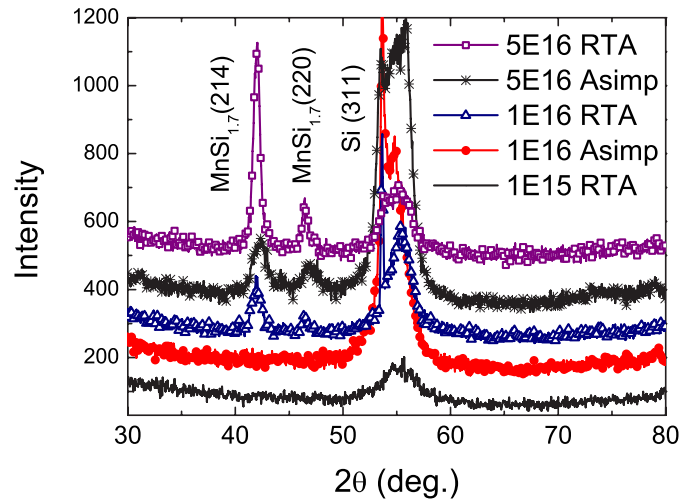

FIG. 5. (Color online) XRD grazing incidence scans of all investigated samples implanted with $\mathrm{Mn}$. In some samples two peaks arise, which can be attributed to Mn-silicide nanoparticles $\left(\mathrm{MnSi}_{1.7}\right)$.

10 to $300 \mathrm{~K}$ (the inset of Figure 6). The ZFC curve shows a gradual increase at low temperature, and reaches a maximum at a temperature of $T_{B}$ (around $23 \mathrm{~K}$ ), while the $\mathrm{FC}$ curve continues to decrease with increasing temperature. At a higher temperature than $T_{B}$, the FC curve merges together with the ZFC curve. Figure 6 also shows a $M-H$ loop taken at $100 \mathrm{~K}$. Below $T_{B}(10 \mathrm{~K})$, these nanoparticles show ferromagnetic behavior, while above $T_{B}(100 \mathrm{~K})$, the $M-H$ loop shows neither cleary remanence nor coercivity, and these nanoparticles are superparamagnetic. The above-mentioned magnetic behavior is typical for systems containing magnetic nanoparticles. ${ }^{20-22}$ Moreover, the wasp-waist shape of the loop is associated with magnetic phases with different coer-

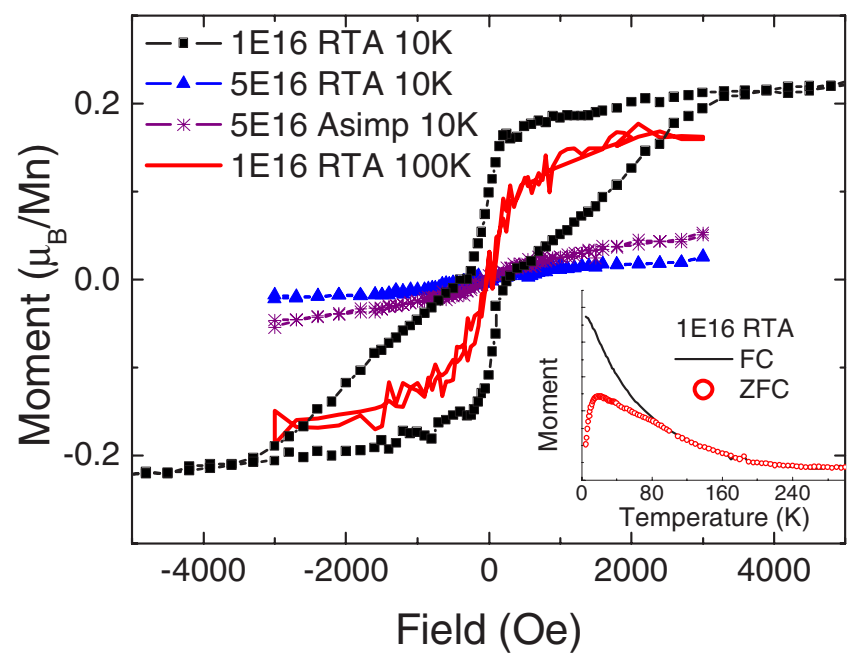

FIG. 6. (Color online) $M-H$ hysteresis loops for Mn-implanted Si samples. Only the sample of 1E16 RTA exhibits a clear hysteretic behavior. Inset: ZFC (open circle) and FC (solid line) magnetization curves reveal a typical characteristic of a magnetic nanoparticle system for the sample of 1E16 RTA. Above the blocking temperature, the sample of 1E16 RTA shows superparamagnetic properties, where neither coercivity nor remanence was observed at $100 \mathrm{~K}$. None of the other samples (1E15 RTA, 1E15 as implanted, and $1 \mathrm{E} 16$ as implanted) exhibit ferromagnetism, even at temperatures down to $10 \mathrm{~K}$ (not shown). 
civities, which could be attributed to the size distribution of nanoparticles as indicated by HRTEM results. ${ }^{23-25}$ Although the sample preparation in our work is identical with Ref. 8, the magnetic properties are drastically different. There could be some other parameters, or technical tricks in sample preparation to result in the discrepancy.

\section{Discussion}

In Table I, all structural and magnetic properties of the investigated samples are listed. Obviously the dependence of magnetization on the fluence and annealing is rather anomalous. In order to explain the magnetization, the magnetic properties for Mn silicides have to be reviewed. Unfortunately, very limited work has been done on the magnetism of $\mathrm{MnSi}_{1.7}{ }^{26}$ In Ref. 26, single crystalline $\mathrm{Mn}_{4} \mathrm{Si}_{7}\left(\mathrm{MnSi}_{1.75}\right)$ were reported to exhibit weak itinerant magnetism with an ordering temperature of $47 \mathrm{~K}$ and with a very low saturation moment of $0.012 \mu_{\mathrm{B}} / \mathrm{Mn}$. For the nanoparticles embedded in $\mathrm{Si}$, i.e., with different surface and/or volume ratio and undergoing different pressure, the magnetism can be much different from bulk crystals. During intense investigations on $\mathrm{MnSi}$ (a weak itinerant magnetic material), the ordering temperature has been found to strongly depend on lattice strain, induced, e.g., by hydrostatic pressure or by the lattice mismatch with substrate. ${ }^{27-30}$ If the exchange interaction is changed for instance by pressure or by alloying, the system no longer orders even at $T=0 \mathrm{~K} .{ }^{27}$ Considering the different grain size of $\mathrm{MnSi}_{1.7}$ in our sample, i.e., different stress provided by the surrounding lattice, we could explain the dependence of the magnetization on the Mn fluence and postim- plantation annealing as follows. Those $\mathrm{MnSi}_{1.7}$ nanoparticles in the sample (1E16 RTA) have a particular medium grain size, i.e., particular lattice deformation or strain, therefore a higher ordering temperature and even a much higher moment $\left(0.21 \mu_{\mathrm{B}} / \mathrm{Mn}\right)$ than the bulk crystal $\left(0.012 \mu_{\mathrm{B}} / \mathrm{Mn}\right)$, while the bigger nanoparticles in the sample of 5E16 RTA are more bulklike and have very weak ferromagnetism. Those smaller $\mathrm{MnSi}_{1.7}$ nanoparticles in other samples (5E16 as implanted and 1E15 RTA) could be in a rather worse crystalline quality or different strain status, and therefore only show weak or nondetectable ferromagnetism. However a nonambiguous reason for the anomalous dependence of the magnetization on the particle size is not yet known.

\section{CONCLUSION}

By investigating $\mathrm{Mn}$-ion implanted $\mathrm{Si}$, we have found a nonsystematic dependence of the induced ferromagnetization on the implantation fluence. There was no significant indication for Mn substituting Si either in the as-implanted or the rapidly annealed samples. The observed ferromagnetism is attributed to $\mathrm{MnSi}_{1.7}$ nanoparticles. The magnetization is maximized at a certain medium grain size of $\mathrm{MnSi}_{1.7}$ nanoparticles, which could result in a particular strain status, consequently a stronger ferromagnetic coupling. Moreover, high resolution analysis techniques are necessary in order to identify those nanoparticles and to clarify the origin of the observed ferromagnetism.

\section{ACKNOWLEDGMENT}

We thank S. Gemming for valuable discussion.
${ }^{1}$ S. J. Pearton, C. R. Abernathy, D. P. Norton, A. F. Hebard, Y. D. Park, L. A. Boatner, and J. D. Budai, Mater. Sci. Eng., R. 40, 137 (2003).

${ }^{2}$ A. H. Macdonald, P. Schiffer, and N. Samarth, Nat. Mater. 4, 195 (2005).

${ }^{3}$ N. Theodoropoulou, A. F. Hebard, M. E. Overberg, C. R. Abernathy, S. J. Pearton, S. N. G. Chu, and R. G. Wilson, Appl. Phys. Lett. 78, 3475 (2001).

${ }^{4}$ M. Venkatesan, C. B. Fitzgerald, J. G. Lunney, and J. M. D. Coey, Phys. Rev. Lett. 93, 177206 (2004).

${ }^{5}$ T. Dietl, H. Ohno, F. Matsukura, J. Cibert, and D. Ferrand, Science 287, 1019 (2000).

${ }^{6}$ F. M. Zhang, X. C. Liu, J. Gao, X. S. Wu, Y. W. Du, H. Zhu, J. Q. Xiao, and P. Chen, Appl. Phys. Lett. 85, 786 (2004).

${ }^{7}$ H. M. Kim, T. W. Kang, and K. S. Chung, J. Ceram. Proc. Res. 5, 238 (2004).

${ }^{8}$ M. Bolduc, C. Awo-Affouda, A. Stollenwerk, M. B. Huang, F. G. Ramos, G. Agnello, and V. P. LaBella, Phys. Rev. B 71, 033302 (2005).

${ }^{9}$ B. E. Egamberdiev and M. Yu. Adylov, Tech. Phys. Lett. 27, 168 (2001).

${ }^{10}$ H. Francois-Saint-Cyr, E. Anoshkina, F. Stevie, L. Chow, K. Richardson, and D. Zhou, J. Vac. Sci. Technol. B 19, 1769 (2001).

${ }^{11}$ Y. C. Lian and L. J. Chen, Appl. Phys. Lett. 48, 359 (1986).
${ }^{12}$ S. Teichert, S. Schwendler, D. K. Sarkar, A. Mogilatenko, M. Falke, G. Beddies, C. Kleint, and H.-J. Hinneberg, J. Cryst. Growth 227-228, 882 (2001).

${ }^{13}$ A. Mogilatenko, Ph.D thesis, Technical University Chemnitz, 2002.

${ }^{14}$ A. Vantomme, M. F. Wu, I. Dézsi, G. Langouche, K. Maex, and J. Vanhellemont, Mater. Sci. Eng., B 4, 157 (1989).

${ }^{15}$ M. F. Wu, J. De Wachter, A.-M. Van Bavel, R. Moons, A. Vantomme, H. Pattyn, G. Langouche, H. Bender, J. Vanhellemont, K. Temst, and Y. Bruynseraede, J. Appl. Phys. 78, 1707 (1995).

${ }^{16}$ J. F. Ziegler, J. P. Biersack, and U. Littmark, The Stopping and Range of Ions in Solids Stopping and Ranges of Ions in Matter Vol. 1 (Pergamon Press, New York 1984).

${ }^{17}$ W. K. Chu, J. W. Mayer, and M. A. Nicolet, Backscattering Spectrometry (Academic, New York, 1978).

${ }^{18}$ M. Eizenberg and K. N. Tu, J. Appl. Phys. 53, 6885 (1982).

${ }^{19}$ B. D. Cullity, Elements of X-ray Diffractions (Addison-Wesley, Reading MA, 1978), p. 102.

${ }^{20}$ M. Respaud, J. M. Broto, H. Rakoto, A. R. Fert, L. Thomas, B. Barbara, M. Verelst, E. Snoeck, P. Lecante, A. Mosset, J. Osuna, T. O. Ely, C. Amiens, and B. Chaudret, Phys. Rev. B 57, 2925 (1998).

${ }^{21}$ Y. Sun, M. B. Salamon, K. Garnier, and R. S. Averback, Phys. Rev. Lett. 91, 167206 (2003). 
${ }^{22}$ P. Dutta, A. Manivannan, M. S. Seehra, N. Shah, and G. P. Huffman, Phys. Rev. B 70, 174428 (2004).

${ }^{23}$ L. H. Bennett and E. D. Torre, J. Appl. Phys. 97, 10E502 (2005).

${ }^{24}$ F. Brem, L. Tiefenauer, A. Fink, J. Dobson, and A. M. Hirt, Phys. Rev. B 73, 224427 (2006).

${ }^{25}$ Shengqiang Zhou, K. Potzger, Gufei Zhang, F. Eichhorn, W. Skorupa, M. Helm, and J. Fassbender, J. Appl. Phys. 100, 114304 (2006).

${ }^{26}$ U. Gottlieb, A. Sulpice, B. Lambert-Andron, and O. Laborde, J. Alloys Compd. 361, 13 (2003).
${ }^{27}$ C. Pfleiderer, S. R. Julian, and G. G. Lonzarich, Nature (London) 414, 427 (2001).

${ }^{28}$ K. Schwinge, C. Mueller, A. Mogilatenko, J. J. Paggel, and P. Fumagalli, J. Appl. Phys. 97, 103913 (2005).

${ }^{29}$ K. Koyama, T. Goto, T. Kanomata, and R. Note, Phys. Rev. B 62 , 986 (2000).

${ }^{30}$ W. Yu, F. Zamborszky, J. D. Thompson, J. L. Sarrao, M. E. Torelli, Z. Fisk, and S. E. Brown, Phys. Rev. Lett. 92, 086403 (2004). 